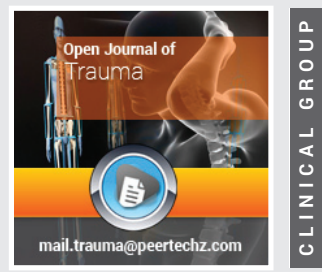

\section{Abdelkader Boukerrouche*}

Department of Digestive Surgery, Hospital of BeniMessous, University of Algiers, Algiers, Algeria

Received: 10 June, 2019

Accepted: 09 July, 2019

Published: 11 July, 2019

*Corresponding author: Abdelkader Boukerrouche, Department of Digestive Surgery, Hospital of BeniMessous, University of Algiers, Algiers, Algeria, Tel: +2136612272 98;

E-mail: aboukerrouche@yahoo.com

Keywords: Damage control surgery; Trauma patient; Lethal triad; Damage control resuscitation

https://www.peertechz.com

Check for updates

\section{Review Article}

\section{Damage control surgery Concept}

\begin{abstract}
Damage control surgery concept (DCS) consists of performing a staged surgery and allowing resuscitation in severe trauma patients who require surgical management. Initially, the DCS has been described in severe liver trauma associated with coagulopathy. Over time, Due to the observed advantages, the DSC approach has become standard practice for abdominal trauma with the extent to extra-abdominal trauma and acute abdominal emergencies. Currently, despite the widespread use by the surgical communities, the indications of DCS strategies have not been clearly defined in the absence of high data level and concerns have hence risen about the overuse and related adverse outcomes of DCS approach in surgical trauma patients. However, Advanced progress in trauma-resuscitation techniques have significantly improved the outcomes and reduced the requirement of DSC strategies in trauma injured patients. In sum, DCS remains an important strategy to surgically manage a specific cohort of patients. The continued research and development in trauma care particularly in patient resuscitation will likely lead to more further decreasing the DCS requirement in severe trauma patients.
\end{abstract}

\section{Introduction}

Traumatic injuries are the leading cause of mortality in people with age under to 44 years. The haemorrhage was the major preventable primary cause of death with $30-40 \%$ of fatalities in traumatically injured patients [1]. Definitive surgery for severe traumatic injuries in the patient with severely physiological disorders is reputed to be detrimental to the outcome and resulting in aggravating the injury and delaying the exhaustion of physiological storage that may cause death [2-4]. The main preoccupation of trauma surgeons was the early and effective control of primary injury and prevention of the secondary injury. The concept of damage control surgery (DCS) had been endorsed as an approach to optimize surgical treatment of severe trauma injured patients with severe physiological disorders and that require surgical intervention [3]. The DCS principles consisted of the early effective primary control of bleeding and abdominal contamination by performing abbreviated surgery; delaying definitive surgery and allowing patient resuscitation and stabilization. The definitive surgery will be achieved once patient physiology has almost been restored [5,6]. The DCS approach incorporates four components including [4]: (1) identification of the unwell trauma patient on the basis of injury characteristics and physiological disorders, (2) controlling bleeding and abdominal cavity contamination by performing abbreviated surgery, (3) continued resuscitation during operation and in the ICU by providing physiological restoration and vital organ support to optimize patient hemodynamic and correct acidosis, hypothermia and coagulopathy. (4) Performing definitive surgery in resuscitated and stabilized patient. The DCS approach has demonstrated improved survival in critically trauma injured and chocked patients $[6,7]$. This approach is currently estimated to be required in $10 \%$ of patients with trauma injuries $[8,9]$. Despite the several advantages, the patients required CDS approach are subjected to multiple surgeries, prolonged ICU stays and may develop abdominal compartment syndrome with acute respiratory distress and multiple organ failure [10]. Clearly, the benefits of the DCS strategies depend on the appropriate indication by selecting the correct patients. As a results research on trauma care specifically the patient resuscitation, the damage control resuscitation (DCR) has been added to DCS approach. This new concept of resuscitation incorporates the early and more aggressive correction of coagulation and metabolic disorders with restriction of isotonic fluids and rapid administration of blood components [11-15]. These advances in early trauma resuscitation have increased the rate of definitive surgery during the initial operation.

\section{History and evolution of damage control surgery conecpt}

The concept of the DCS emerged from the clinical achievement of liver trauma management in the later1970s $[16,17]$.As a favourable result from clinical experiences and observations, staged laparotomy with perihepatic packing to achieve haemostasis became widespread in liver trauma $[16,17]$. However, the benefit of intra-abdominal packing and delayed definitive surgery on patient survival in liver trauma has been proved later in 1981. Uncontrolled bleeding and refractory coagulopathy had been also identified as the major 
cause of death of liver trauma patients $[18,19]$. In fact, the perihepatic packing technique has been advocated as a life-saving method in severe liver trauma with refractory coagulopathy $[20,21]$.So the fundamental objective of staged laparotomy and delayed reconstructive surgery has been to rapidly allow the patient physiology restoration and coagulopathy correction.In penetrating abdominal trauma, the benefit of staged surgery on patient survival has firstly been outlined in 1983 [22] Compared to definitive laparotomy, staged surgery has been associated with a benefit on survival in patients who developed intraoperative coagulopathy, and the definitive surgery has been completed once the coagulation returned to normal level [22].In addition to coagulopathy, it has been observed that death was exacerbated by hypothermia and metabolic acidosis. Therefore, emphasizing hypothermia and metabolic acidosis have been proposed as key factors to promote lethal coagulopathy [4].A decade after and in 1993, the concept of 'Damage Control Surgery' has been clearly described in trauma care by Rotondo et al. by outlining the three-phase approach [6]. This three-phase approach consisted of, staged surgery with the first control of bleeding and intestinal content spillage, patient physiological restoration and optimization, and performing definitive surgery on resuscitated and stabilized patient [6].The staged surgery for induced injury coagulopathy was widely accepted as a care practice in trauma patients [7,23,24]. Furthermore, patient survival has markedly been improved by the implementation of this practice approach (DCS) in major abdominal trauma injuries [6,7,23,24].The patient resuscitation was considered as a crucial step of the damage control surgery concept. It must be started in the emergency room and continued in the intra and postoperative period. However, the shocked patient with major trauma who received excessive fluid volumes (crystalloids) experienced a subsequent pulmonary and intestinal tissue oedema [25,26]. In addition to intestinal oedema and large volume resuscitation, a tightly packed and closed abdomen led to increasing the intraabdominal pressure and the development of the abdominal compartment syndrome (ACS) [27,28]. The reported ACS incidence was superior to $30 \%$ and associated mortality was greater than $60 \%$ in major trauma patients [ 24]. The death resulted from ACS complications such as respiratory, renal and cardiac failure. Over time, the combined use of open abdomen surgery and modified traumatic shock resuscitation techniques have increasingly reduced the incidence of lethal ACS syndrome [29].Therefore the prevention of the lethal ACS constitutes the greatest documented achievement of the modern post injury critical care.Over the last 10 years, the research conducted on ACS and advances in trauma shock resuscitation had led to adding the damage control resuscitation approach (DCR) to the damage control paradigm. Compared to previously described resuscitation, the DCR consisted of early and more aggressive correction of coagulopathy and metabolic disorders. The isotonic fluid restriction for plasma volume expansion, permissive hypotension, early and rapid administration of blood components to correct post-traumatic coagulation disorders are the key concepts of the DCR [11]. DCR allows the restoration of normal patient physiology and early correction of the post- traumatic bloody vicious cycle, facilitating the completion of definitive surgery at the first operation with reduced perioperative morbidity and improved outcomes [ 13,15,30]. This strategy starts in the emergency room and continues during the surgical procedure and in the ICU [12].The DCS is now considered as a component of DCR and its benefit is now well demonstrated in the context of DCR.Indeed DCS combined to DCR form the modern trauma care continuum.[31,32]. The recently published reports ( 2011) showed the clear benefits of DCS on survival in injured patients who have been managed with DCR compared to conventional resuscitation methods [33].Also, the stay length in ICU has increasingly been reduced in patients requiring DCS and managed with DCR [30].DCR implementation in a specifically selected patient who required emergency surgery for trauma has significantly decreased the need for DCS laparotomy and reduced mortality and increased the rate of definitive surgery at the first operation in level 1 trauma centre [34]. The shift towards performing complete surgery was associated with significant reductions in health care costs and resources utilization.Additionally, important studies reported higher rates of primary abdominal closure in the context of DCR approach [35,36].More recently and related to continued advances in trauma care, the DCR strategies have reduced the need for surgical haemostasis in severe liver trauma $(>20 \%$ ) by the direct address of trauma-induced coagulopathy, increased the rate of definitive surgery and reduced the need for DCS approach in a critically injured patient [37].

\section{Damage control surgery indications and current evi- dence data-base}

The DCS has become a standard approach in trauma care only on the basis of clinical experiences and observations. Until 2014, and due to the lack of high evidence level from the published studies comparing DCS approach to immediate definitive surgery, the DCS practice has not been validated in major abdominal trauma [38]. Indeed the indications for DCS were historically based on patient factors (physiology reserve, comorbidities), injury factors (blunt vs penetrating trauma, peritoneal contamination, major bleeding), physiological parameters ('lethal triad of trauma' -hypothermia, acidosis, coagulopathy), and treatment factors such as resuscitation requirements (volume and type of administrated fluids) and expected duration/physiological effect of definitive care $[31,38,39,40]$.In addition, the $\mathrm{PH}$ level, hypothermia, administrated volume fluid and transfusion have been showed to be sensitive indicators of patient prognosis [41,42]. The indications for damage control strategies have been increased with the growing opinion that these strategies should be made early, prior to irreversible physiological compromise [43]. Despite its accepted benefits, the overuse of DCS in trauma practice has resulted in augmentation of complications and resource utilization [44]. These variations in the indication of DCS were attributables to the lack of consensus on the appropriate use of this treatment approach among the surgical community [45]. Regarding the large variations in the indications of the DCS strategies, a panel of trauma surgery experts reviewed the peer-reviewed papers published between 1983 and 2014 in order 
to synthesize and rate the appropriateness of DCS indications in surgical practice for civilian trauma [41]. The studies involving exclusively non-civilian trauma, neurological and orthopaedic injured population are excluded from analysis. The report of trauma surgery expert panel suggested that the indications for DCS should be defined on the basis of several factors including the preoperative transfusion of more than 10 units of PRBCs, administration of more than $12 \mathrm{l}$ of PRBCs/ whole blood/ other blood product/ crystalloids during the pre and intraoperative phase, bleeding uncontrollable with conventional treatment methods, and the degree of physiological disorders as demonstrated by pre or intraoperative hypothermia $(<34.88 \mathrm{C})$, acidosis $(\mathrm{pH}<7.2)$ and/or coagulopathy (prothrombin time and partial thromboplastin time $>1.5 \mathrm{x}$ normal and the absence of visible blood clots during operation/ diffuse oozing from all injured tissues). Specific injury characteristics as severe multiple injuries (ISS $\geq 25$ ), associated severe hemorrhagic shock (diastolic pressure $<70 \mathrm{mmHg}$ ) on admission, abdominal and thoracic compartment syndrome were also an indication to DCS. The prolonged operative procedure more than 90 min with partial response to resuscitation was interestingly considered as an indication for DCS. Difficulties to make the appropriate decision regarding the treatment priorities in the presence of severe and complicated injury and limited technical conditions. In sum, the DCS approach should be applied in the presence of the previously described prognosis factors, and the surgical management strategy must be based on the dynamic response to resuscitation rather than the patient physiology indicators or injury characteristic at the presentation. Due to the absence of high-level evidence data regarding the appropriate indications, a recent report (2017) highlighted the inconsistent use of the DCS approach with significant variation across tertiary trauma centres [46]. However, the damage control strategy remains primordial in the management of shocked patients or those not responding to intensive resuscitation. As acknowledged by authors, the benefits of DCR on patient physiology and survival in trauma care currently constitute a domain of active investigation and clinical research [14,47-49]. Therefore, further original research studies are required to validate the indications of the DCS strategy on the basis of evidence-based results.

\section{Damage control surgery and abdominal emergencies}

The DCS strategies have been widely used in abdominal trauma injuries with well-demonstrated benefits on patient survival. During the last 15 years, efforts have been made to manage the patients presenting acutely surgical abdominal emergencies associated with a physiological compromise by using the DCS approach [50]. However, the published results of a few studies with a reduced sample of the population are preliminary and inconclusive regarding the definitions and principles of DSC strategies in the context of surgical abdominal emergencies [51,52]. Oppositely, published individual experiences on the DCS approach, showed real benefits on patient survival [53,54]. Therefore, despite the lack of evidence-based data, the trends towards the adoption of DCS strategies in abdominal surgical emergencies are comparable to those seen in the damage control orthopaedic approach (DCO) for trauma care before its spread and acceptance as a treatment strategy in orthopaedic trauma.

\section{References}

1. Kauvar DS, Lefering R, Wade CE (2006) Impact of hemorrhage on trauma outcome: an overview of epidemiology, clinical presentations, and therapeutic considerations. J Trauma 60: S3-S11. Link: http://bit.ly/2XVEKS6

2. Mikhali J (1999) The trauma triad of death: hypothermia, acidosis and coagulopathy. ACCN Clin Issues 10: 85-94. Link: http://bit.ly/30nGGQO

3. Chovanes J, Cannon JW, Nunez TC (2012) The evolution of damage control surgery. Surg Clin North Am 92: 859-875. Link: http://bit.ly/30qGAlc

4. Moore EE (1996) Thomas G. Orr Memorial Lecture. Staged laparotomy for the hypothermia, acidosis, and coagulopathy syndrome. Am J Surg 172: 405410. Link: http://bit.ly/2YQtKmc

5. Rotondo MF, Zonies DH (1997) The damage control sequence and underlying logic. Surg Clin North Am 77: 761-777. Link: http://bit.ly/32fhPAB

6. Rotondo MF, Schwab CW, McGonigal MD, Phillips GR 3rd, Fruchterman TM, et al. (1993) Damage control': an approach for improved survival in exsanguinating penetrating abdominal injury. J Trauma 35: 375-382. Link: http://bit.ly/2XIrpbA

7. Burch JM, Ortiz VB, Richardson RJ, Martin RR, Mattox KL, et al. (1992) Abbreviated laparotomy and planned reoperation for critically injured patients. Ann Surg 215: 476-483. Link: http://bit.ly/2YMGpqr

8. Sagraves SG, Toschlog EA, Rotondo MF (2006) Damage control surgery: the intensivist's role. J Intensive Care Med 21: 5-16. Link: http://bit.ly/2LPfXsf

9. Jaunoo SS, Harji DP (2009) Damage control surgery. Int J Surg 7: 110-113. Link: http://bit.ly/32hiTE9

10. Smith BP, Adams RC, Doraiswamy VA (2010) Review of abdominal damage control and open abdomens: focus on gastrointestinal complications. J Gastrointestin Liver Dis 19: 425-435. Link: http://bit.ly/30pOSQH

11. Holcomb JB, Jenkins D, Rhee P (2007) Damage control resuscitation: directly addressing the early coagulopathy of trauma. J Trauma 62: 307-310. Link: http://bit.ly/2JsEBOs

12. Kaafarani HM, Velmahos GC (2014) Damage control resuscitation in trauma Scand J Surg 103: 81-88. Link: http://bit.ly/2YSyOlm

13. Duchesne JC, Islam TM, Stuke L (2009) Hemostatic resuscitation during surgery improves survival in patients with traumatic-induced coagulopathy J Trauma 67: 33-37. Link: http://bit.ly/2XCbbFP

14. Rajasekhar A, Gowing R, Zarychanski R (2011) Survival of trauma patients after massive red blood cell transfusion using a high or low red blood cell to plasma transfusion ratio. Crit Care Med 39: 1507-1513. Link: http://bit.ly/2G7WejV

15. Mizobata Y (2017) Damage control resuscitation: a practical approach for severely hemorrhagic patients and its effects on trauma surgery. $\mathrm{J}$ Intensive Care 5: 4. Link: http://bit.ly/2Jt4U6x

16. Lucas CE, Ledgerwood AM (1976) Prospective evaluation of hemostatic techniques for liver injuries. J Trauma 16: 442-451. Link: http://bit.ly/2xIMsjM

17. Walt AJ (1978) Founder's lecture: the mythology of hepatic trauma: or Babel revisited. Am J Surg 135: 12-18. Link: http://bit.ly/2XEOK2B

18. Elerding SC, Aragon GE, Moore EE (1979) Fatal hepatic hemorrhage after trauma. Am J Surg 138: 883-888. Link: http://bit.ly/2xFy8sh

19. Kashuk JL, Moore EE, Millikan JS, Moore JB (1982) Major abdomina vascular trauma: a unified approach. J Trauma 22: 672-679. Link: http://bit.ly/2XGaWtq

20. Feliciano DV, Mattox KL, Jordan GL (1981) Intra-abdominal packing for control of hepatic hemorrhage: a reappraisal. J Trauma 21: 285-290. Link: http://bit.ly/32kdqw7 
21. Svoboda JA, Peter ET, Dang CV (1982) Severe liver trauma in the face of coagulopathy. A case for temporary packing and early reexploration. Am J Surg 144: 717-721. Link: http://bit.ly/2G2Rr3p

22. Stone HH, Strom PR, Mullins RJ (1983) Management of the majo coagulopathy with onset during laparotomy. Ann Surg 197: 532-535. Link: http://bit.ly/2XHwSQ3

23. Cue JI, Cryer HG, Miller FB (1990) Packing and planned reexploration for hepatic and retroperitoneal hemorrhage: critical refinements of a usefu technique. J Trauma 30: 1007-1011. Link: http://bit.ly/30rEUhB

24. Morris JA, Eddy VA, Blinman TA (1993) The staged celiotomy for trauma. Issues in unpacking and reconstruction. Ann Surg 217: 576-584. Link: http://bit.ly/2G6biyy

25. Shoemaker WC, Appel PL, Kram HB (1988) Prospective trial of supranorma values of survivors as therapeutic goals in high-risk surgical patients. Chest 94: 1176-1186. Link: http://bit.ly/2JEgiv8

26. Bishop MH, Shoemaker WC, Appel PL, Wo CJ, Zwick C, et al. (1993) Relationship between supranormal circulatory values, time delays, and outcome in severely traumatized patients. Crit Care Med 21: 56-63. Link: http://bit.ly/2G6bq10

27. Balogh Z, McKinley BA, Cocanour CS, Kozar RA, Valdivia A, et al. (2003) Supranormal trauma resuscitation causes more cases of abdominal compartment syndrome. Arch Surg 138: 637-642. Link: http://bit.ly/2XEIZIz

28. Balogh ZJ, Lumsdaine W, Moore EE, Moore FA (2014) Postinjury abdominal compartment syndrome: from recognition to prevention. Lancet 384: 14661475. Link: http://bit.ly/2LfsRQO

29. Balogh ZJ, Martin A, van Wessem KP (2011) Mission to eliminate postinjury abdominal compartment syndrome. Arch Surg 146: 938-943. Link: http://bit.ly/2LMtUqV

30. Duchesne JC, Kimonis K, Marr AB (2010) Damage control resuscitation in combination with damage control laparotomy: a survival advantage. J Trauma 69: 46-52. Link: http://bit.ly/2Y187IS

31. Duchesne JC, McSwain NE, Cotton BA, Hunt JP, Dellavolpe J, et al. (2010) Damage control resuscitation: the new face of damage control. J Trauma 69: 976-990. Link: http://bit.ly/30wRMTU

32. Jansen JO, Thomas R, Loudon MA, Brooks A (2009) Damage control resuscitation for patients with major trauma. BMJ 338: b1778. Link http://bit.ly/2LgscPb

33. Cotton BA, Reddy N, Hatch QM, Le Febvre E, Wade CE, et al. (2011) Damage control resuscitation is associated with a reduction in resuscitation volumes and improvement in survival in 390 damage control laparotomy patients. Ann Surg 254: 598-605. Link: http://bit.ly/30sVTA1

34. Higa G, Friese R, O'Keeffe T, Wynne J, Bowlby P, et al. (2010) Damage control laparotomy: a vital tool once overused. J Trauma 69: 53-59. Link: http://bit.ly/30mKNg6

35. Ball CG, Dente CJ, Shaz B (2013) The impact of a massive transfusion protocol $(1: 1: 1)$ on major hepatic injuries: does it increase abdominal wall closure rates? Can J Surg 56: E128-E134. Link: http://bit.ly/2XFwlxa

36. Bradley M, Galvagno S, Dhanda A, Rodriguez C, Lauerman $M$, et al (2014) Damage control resuscitation protocol and the management of open abdomens in trauma patients. Am Surg 80: 768-775. Link: http://bit.ly/2JrsTmO

37. Shrestha B, Holcomb JB, Camp EA, Del Junco DJ, Cotton BA, et al. (2015) Damage-control resuscitation increases successful nonoperative management rates and survival after severe blunt liver injury. J Trauma Acute Care Surg 78: 336-341. Link: http://bit.ly/2xGUHg2
38. Roberts DJ, Bobrovitz N, Zygun DA, Ball CG, Kirkpatrick AW, et al. (2015) Indications for use of damage control surgery and damage control interventions in civilian trauma patients: a scoping review. J Trauma Acute Care Surg 78: 1187-1196. Link: http://bit.ly/2JtpFPA

39. Waibel BH, Rotondo MM (2012) Damage control surgery: it's evolution ove the last 20 years. Rev Col Bras Cir 39: 314-321. Link: http://bit.ly/2JrtuF4

40. Cirocchi R, Montedori A, Farinella E (2013) Damage control surgery for abdominal trauma. Cochrane Database Syst Rev CD007438. Link: http://bit.ly/2S7Jv5C

41. Roberts DJ, Bobrovitz N, Zygun DA, (2016) Indications for use of damage control surgery in civilian trauma patients: a content analysis and expert appropriateness rating study. Ann Surg 263: 1018-1027. Link: http://bit.ly/2xGGhNh

42. Ordoñez CA, Badiel M, Sánchez Al (2011) Improving mortality predictions in trauma patients undergoing damage control strategies. Am Surg 77: 778782. Link: http://bit.ly/2XHPy1S

43. Godat L, Kobayashi L, Costantini T, Coimbra R (2013) Abdominal damage control surgery and reconstruction: world society of emergency surgery position paper. World J Emerg Surg 8: 53. Link: http://bit.ly/2YN9qlL

44. Hatch QM, Osterhout LM, Podbielski J, Kozar RA, Wade CE, et al. (2011) Impact of closure at the first take back: complication burden and potential overutilization of damage control laparotomy. J Trauma 71: 1503-1511. Link: http://bit.ly/2XFhrwC

45. Birkmeyer JD, Reames BN, McCulloch P (2013) Understanding of regional variation in the use of surgery. Lancet 382: 1121-1129. Link: http://bit.ly/2JrAly1

46. Watson JJ, Nielsen J, Hart K (2017) Damage control laparotomy utilization rates are highly variable among level I trauma centers: pragmatic, randomized optimal platelet and plasma ratios findings. J Trauma Acute Care Surg 82 481-488. Link: http://bit.ly/2YIXKAm

47. Da Luz LT, Nascimento B, Shankarakutty AK (2014) Effect of thromboelastography (TEG(R)) and rotational thromboelastometry $(\operatorname{ROTEM}(\mathrm{R}))$ on diagnosis of coagulopathy, transfusion guidance and mortality in trauma: descriptive systematic review. Crit Care 18: 518 . Link: http://bit.ly/2NWPz2G

48. Khan S, Brohi K, Chana M, Raza I, Stanworth S, et al. (2014) Hemostatic resuscitation is neither hemostatic nor resuscitative in trauma hemorrhage. J Trauma Acute Care Surg 76: 561-567. Link: http://bit.ly/2XYUpQw

49. Holcomb JB, Tilley BC, Baraniuk S (2015) Transfusion of plasma, platelets, and red blood cells in a 1:1:1 vs a 1:1:2 ratio and mortality in patients with severe trauma: the PROPPR randomized clinical trial. JAMA 313: 471-482. Link: http://bit.ly/2G9t7g6

50. Waibel $\mathrm{BH}$, Rotondo MF (2012) Damage control for intra-abdominal sepsis. Surg Clin North Am 92: 243-257. Link: http://bit.ly/2XE5110

51. Weber DG, Bendinelli C, Balogh ZJ (2014) Damage control surgery for abdominal emergencies. $\mathrm{Br} J$ Surg 101: e109-e118. Link: http://bit.ly/2G60Ze0

52. Person B, Dorfman T, Bahouth H (2009) Abbreviated emergency laparotomy in the non-trauma setting. World J Emerg Surg 4: 41. Link: http://bit.ly/2XIIP9g

53. Stawicki SP, Brooks A, Bilski T (2008) The concept of damage contro: extending the paradigm to emergency general surgery. Injury 39: 93-101. Link: http://bit.ly/2LKLeg9

54. Morgan K, Mansker D, Adams DB (2010) Not just for trauma patients: damage control laparotomy in pancreatic surgery. J Gastrointest Surg 14: 768-772. Link: http://bit.ly/2XGdbgk

Copyright: (C) 2019 Boukerrouche A. This is an open-access article distributed under the terms of the Creative Commons Attribution License, which permits unrestricted use, distribution, and reproduction in any medium, provided the original author and source are credited. 